\title{
Manufacture of Water-Resistant Corrugated Board Boxes for Agricultural Products in the Cold Chain System
}

\author{
Jung-Yeon Jo ${ }^{\dagger}$, Choon-Ki Min, and Jun-Seop Shin \\ Received March 7, 2012; Received in revised form March 25, 2012; Accepted April 9, 2012
}

\begin{abstract}
For the purpose of developing liner board for water-resistant corrugated board in the cold chain system, several types of base paper for corrugated board were purchased from the market and 6 different boards were produced in the paperboard mill by applying the chemicals on the base paper. Then, water-moisture resistant performance and physical properties of the boards were compared each other.

The liner board which is dried at high temperature with pressure by Condebelt papermaking system(CK paper) showed a superior performance in strength over common liner boards. Strength of the board increased by surface chemical treatment up to $60 \%$ of compressive strength and $30 \%$ of bursting strength. Starch insolubilization with Ammonium-Zirconium Carbonate(AZC) and surface coating with a surface size and a moisture resistant chemical on CK paper showed the best result. Therefore, this method was recommended to produce the outer liner board for water -resistant corrugated board.
\end{abstract}

Keyword : Water-resistant corrugated board, Cold chain system, Starch insolubilization, CK paper, Compressive strength

\section{Introduction}

A major limitation in using corrugated boxes for the packaging of perishable produce such as fruits and vegetables is that their performance is greatly reduced when wet or kept at high humidity. Boxes containing agricultural products need to be stored and transported at high humidity and low temperature, so that their contents reach the customer in good condition. In-service failure in these situations is mainly the result of compressive strength reduction caused by dewforming phenomenon at surface of corrugated board liner. Compressive strength reduction becomes more severe when the humidity is cycled such as cold chain system.

From structural mechanics point of view, corrugated board is regarded as a simple sandwich construction at the micro scale and represents a complex mechanical behavior when the surrounding temperature and relative humidity vary. The fiber and fiber network

\footnotetext{
- Department of Packaging \& Distribution Yong-In Songdam College Mapyoung-Dong 571-1, Yongin-Si Kyoungki-Do, 449-710, Korea

† Corresponding author E-mail : jjy@ysc.ac.kr
} 
strength, the mechanical properties, and the life of the packaging are greatly reduced with the increase not only of moisture content in the paper but of the relative humidity surrounding the corrugated board.

As reviewed in previous experimental studies, ${ }^{1,2}$ chemical treatments have been made for strength enhancement of corrugated boards. However, these treatments, for example, wet-end additives or surface size application were not successful in developing compressive strength and water-resistant property of corrugated boards. in the cold chain system, because water and moisture could not be prevented from penetrating through air ventilation holes of corrugated boxes for precooling and from weakening the bonding strength of starch adhesive between liner and corrugating medium with the treatments alone.

Therefore, the objective of this study was to investigate the effectiveness of chemicals treatments on top liner surface and insolubilization of starch adhesives to improve the water-resistant performance and mechanical properties of corrugated board boxes for agricultural products in the cold chain system. This has been done by surface treatments on pre-made liner boards with several chemicals, and then by determining the water or moisture resistant performance and physical properties under the condition simulated the cold chain system.

\section{Materials \& Methods}

\subsection{Base paper and chemicals}

The ten types of base papers for corrugated board
Table 1. Base paper used in the experiment

\begin{tabular}{ccl}
\hline No & Base paper & \multicolumn{1}{c}{ Treatments } \\
\hline 1 & CK180 & No \\
2 & CK180 & Moisture resistance \\
3 & CK180 & $\begin{array}{l}\text { Moisture resistance +Starch } \\
\text { insolubilization }\end{array}$ \\
& & Moisture resistance + Surface sizing \\
4 & CK180 & +Starch insolubilization \\
5 & K180 & Moisture resistance \\
6 & K180 & Starch insolubilization \\
7 & K180 & No \\
8 & SK180 & Moisture resistance \\
9 & SK180 & No \\
10 & B160 & No \\
\hline
\end{tabular}

liner were used in this study as shown in Table 1.

No treated papers of $160 \mathrm{~g} / \mathrm{m}^{2}$ (No.10) or 180 $\mathrm{g} / \mathrm{m} 2$ (No.1, 7, and 9) were used in this study as original base papers, which were purchased from Dong-Il

Table 3. Surface coating condition at size press

\begin{tabular}{lc}
\hline \multicolumn{1}{c}{ Item } & Condition \\
\hline Starch type & $\begin{array}{c}\text { Tapioca oxidized } \\
\text { starch }\end{array}$ \\
Conc. of starch sol'n(\%) & 10 \\
Speed(m/min) & 550 \\
Nip pressure $(\mathrm{kg} / \mathrm{cm})$ & 50 \\
Spraying pressure $(\mathrm{bar})$ & 2.5 \\
Spraying height(mm) & 500 \\
S/P coating weight(L/min) & 157 \\
Starch coating weight(\%) & $4($ one side : $\%)$ \\
Chemical dosage(\%) & 5 \\
(based on starch, AZC, surface size) & \\
\hline
\end{tabular}

Table 2. Specifications of chemicals used in the experiment

\begin{tabular}{cccc}
\hline & Moisture resistant agent & Starch insolubilizer & Surface size \\
\hline Chemical composition & Acryl derivative & AZC & Modified acryl copolymer \\
Solid(\%) & 40.0 & 30.0 & 35.0 \\
$\mathrm{pH}$ & 9.0 & 10.0 & 4.0 \\
Viscosity(cPs) & 200 & 10 & 1000 \\
\hline
\end{tabular}


Paper Co. Mfg.

Then, a known volume of prepared solution containing the required levels of surface size and moisture resistant agent was subsequently applied to two sides of a base paper using a size press in Dong-Il Paper Co. Mfg.(Ansan Mill). And the performance of insolubilizer(AZC) which was added to the cooked starch solution was investigated. The specifications of some chemicals used in this study were shown in Table 2.

\subsection{Size press coating condition}

The coating conditions of the surface size are shown in Table 3.

\subsection{Moisture-resistant chemical treatment}

A part(No.2, 3, 4, 5, and 8) of base papers as mentioned above was transferred to an air-knife coater and $6 \mathrm{~g} / \mathrm{m}^{2}$ of moisture-resistant was applied on top side of the base paper. The operating condition of the air-knife coater is shown in Table 4.

\subsection{Measurement of physical properties}

After conditioning of corrugated base papers in a chamber under three different relative humidity $(50,65$ and $80 \%)$ respectively at a constant temperature( 2 $0{ }^{\circ} \mathrm{C}$ ), the physical properties such as bursting strength, compressive strength(ring crush), water vapor transmission rate, and water absorbancy were determined by ISO and TAPPI standard methods.

\section{Results \& Discussion}

\subsection{Basis weight}

Table 4. Operating condition of air-knife coater

\begin{tabular}{lc}
\hline \multicolumn{1}{c}{ Item } & Condition \\
\hline Coating speed $(\mathrm{m} / \mathrm{min})$ & 200 \\
Dryer type & Air flotation dryer \\
Drying temperature $\left({ }^{\circ} \mathrm{C}\right)$ & 160 \\
Coating weight $($ one side $)\left(\mathrm{g} / \mathrm{m}^{2}\right)$ & 6 \\
\hline
\end{tabular}

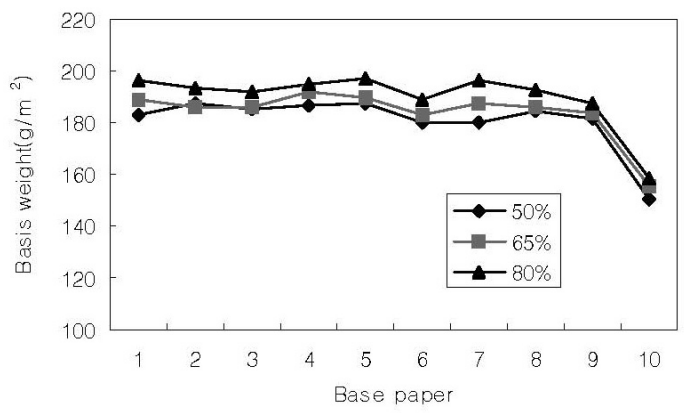

Fig. 1. Changes of basis weight of base paper by relative humidity.

Most papers except No. 10 appeared to be more than $180 \mathrm{~g} / \mathrm{m}^{2}$ in grammage at $65 \%$ relative humidity $(\mathrm{RH})$ as shown in Fig. 1. No. 4 paper represented the highest basis weight among 10 papers at $65 \% \mathrm{RH}$ since it was coated with 3 different chemicals. The grammage increase of No. 4, when RH was increased to $80 \%$ from $65 \%$, was the lowest, which means the superior water-moisture resistance of the paper.

\subsection{Moisture content}

There was little difference of moisture content between CK papers at 50\% RH. At higher $\mathrm{RH}(80 \%)$, the moisture content of No. 4 paper represented the lowest value as shown in Fig. 2, which is due to better moisture resistance performance of the paper than others. The good moisture resistant performance of No. 4 paper can be interpreted not only by the effect of chemical treatments but by the property of CK paper

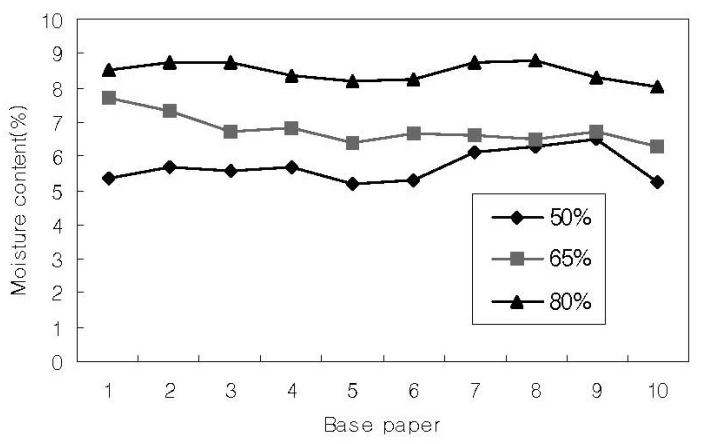

Fig. 2. Changes of moisture content of base paper by relative humidity. 
which is dried by the Condebelt process with higher sheet density, surface smoothness and humidity resistance than conventionally dried ones.

\subsection{Density}

The Condebelt drying process, which was originally designed for improved drying rate, has been found to have a wide range of positive effects on sheet properties mainly because it dries the web at such a elevated pressure and temperature which are not attainable in conventional cylinder drying. The z-directional pressure and temperature have been found to plasticize not only cellulose and hemicellulose but also lignin, which increases fiber flattening, web

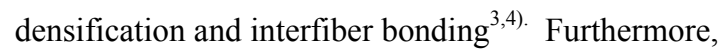
the Condebelt dryer dries the sheet in a such a fully restraint condition that improves cross machine direction stiffness, which is critical for compressive strength of corrugated containers. ${ }^{5}$

CK paper represented the highest density followed by K, SK and B papers in the order as shown in Fig. 3. The higher density of CK was due to the Condebelt drying which is performed at high temperature and pressure. Since the density of paper is proportional to compressive and tensile strengths of the paper, $\mathrm{CK}$ was thought to be more suitable for liner and flute.

\subsection{Water vapor transmission rate}

Moisture resistance treatment on the surface of outer

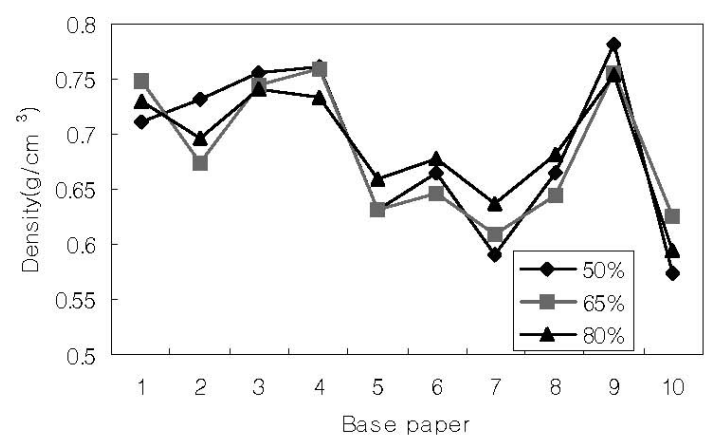

Fig. 3. Changes of density of base paper by relative humidity.

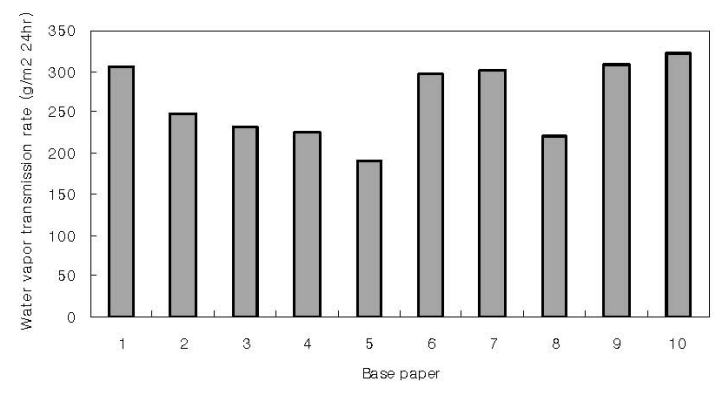

Fig. 4. Changes of water vapor transmission rate of base paper by relative humidity.

liner was the most critical factor to water vapor transmission rate ocorrugated board with the comparison of the results of No. 5, 6 and 7 papers as shown in Fig. 4. A single use of starch insolubilizer or surface size was not enough to enhance moisture resistance of paper remarkably. Using the treatments mentioned above in conjunction with moisture resistance treatment represented an additional increase of moisture resistance of paper compared to the single treatment.

\subsection{Compressive strength}

CK paper showed the highest compressive strength followed by SK, $\mathrm{K}$ and $\mathrm{B}$ paper in that order. Insolubilization of starch adhesive(No. 3, 6) was the most influential treatment to improve compressive strength of paper at $50 \% \mathrm{RH}$ as shown in Fig. 5. At higher $\mathrm{RH}(80 \%)$, No. 4 paper treated with starch insolubilizer, moisture resistant agent and surface size

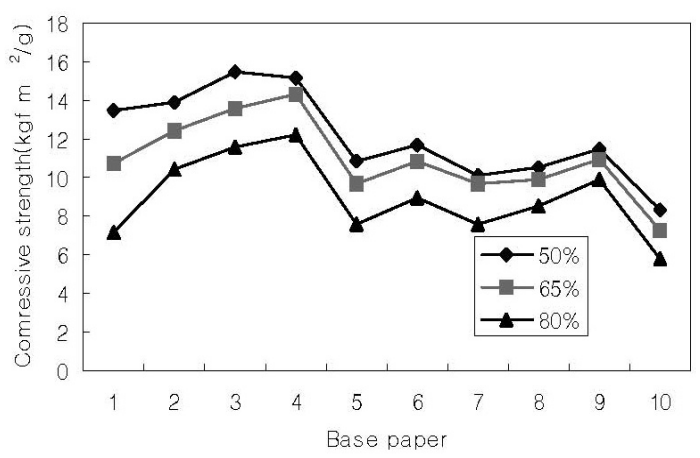

Fig. 5. Changes of compressive strength of base paper by relative humidity. 
represented the best result. There were little improvement of the compressive strength from the water resistance treatment alone on paper except $\mathrm{CK}$ paper. Compressive strength were able to be increased by $10 \%(\mathrm{RH} 50 \%) \sim 60 \%(\mathrm{RH} 80 \%$ ) depending on the chemical treatments, and it's effect is proportional to the extent of RH.

Moisture resistance treatment was not effective in minimizing the compressive strength decrease with the increase of RH, while starch insolubilization was very effective for the same purpose(No. 6, 7).

\subsection{Burst strength}

SK paper showed slightly higher burst strength than CK paper. Starch adhesive insolubilization increased burst strength of paper the most among the treatments as shown in Fig. 6. With CK paper, burst strength could be increased by $30 \%(\mathrm{RH} 50 \%$ ) by chemical treatments. The increase rate was the highest at $50 \% \mathrm{RH}$ and in inverse proportion to RH. Contrary to the results of compressive strength, moisture resistance and starch insolubilization treatment were effective in minimizing the compressive strength decrease with the increase of RH(No. 5, 6 and 7).

\subsection{Water absorbency}

Cobb value was greatly influenced by the moisture resistance treatment, while starch insolubilization and surface sizing treatments were ineffective. Regardless

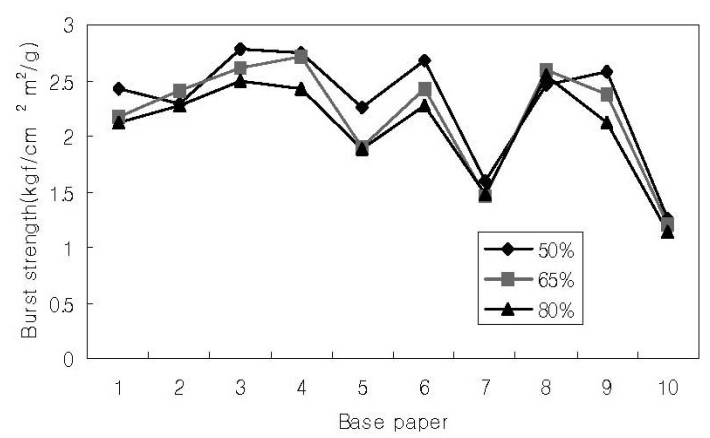

Fig. 6. Changes of burst strength of base paper by relative humidity.

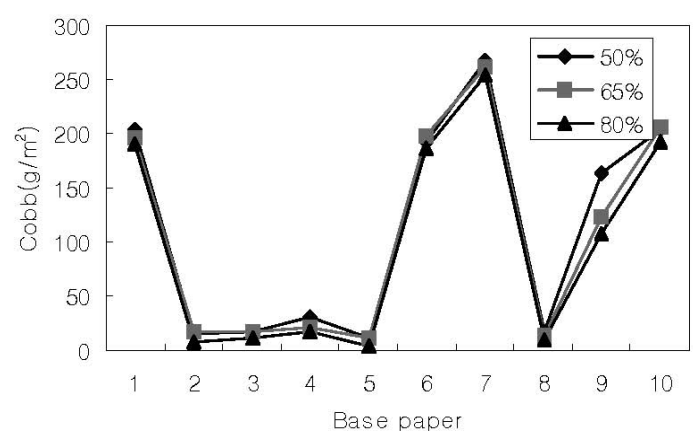

Fig. 7. Changes of water absorbency of base paper by relative humidity.

of base paper, moisture resistance treated papers represented a sharp decrease in Cobb value and little changes with the increase of RH as shown in Fig. 7.

\section{Conclusion}

To develop liner board for water resistant corrugated board in the cold chain system, several types of base paper for corrugated board were purchased from the market and 6 different boards were produced in the mill by applying chemical treatments including moisture resistance, starch adhesive insolubilization, and surface sizing, chosen in the previous studies, on the base paper. Then water-moisture resistance and physical properties of the boards kept under the varied relative humidity were compared each other.

The liner board dried by the Condebelt(CK paper) showed a superior performance in strength over conventional liner boards. Strength of the board increased by surface chemical treatment up to $60 \%$ of compressive strength and $30 \%$ of burst. Starch insolubilization with Ammonium-Zirconium Carbonate and surface coating with a surface size and a moisture resistant chemical on $\mathrm{CK}$ paper showed the best performance. Therefore this method was recommended to produce the outer liner board for water resistant corrugated board. 


\section{Literature Cited}

1. Jung-Yeon Jo, Choon-Ki Min, and Jun-Seop Shin, Manufacture of Water-Resistant Corrugated Board Boxes for Agricultural Products in the Cold Chain System(I) - Effects of Fiber Types, Wet Strength Agents and a Moisture-Proof Chemical on the Physical Properties of Base papers for Corrugated Board Boxes -, Journal of Korea TAPPI 35(2):26 32(2003)
2. Jung-Yeon Jo, Choon-Ki Min, and Jun-Seop Shin, Manufacture of Water-Resistant Corrugated Board Boxes for Agricultural Products in the Cold Chain System(II) - Application Methods of Chemicals for Improving Water and Moisture Resistance of Corrugated Boards -, Journal of Korea TAPPI 36(2):60 69(2004)

3. Horn, R. A., Tappi 62(7) : 77(1979).

4. Byrd, V.L., Tappi 62(7) : 81(1979).

5. Kunnas, L., Lehtinen, J., Paulapuro, H. and Krviranta, A., Tappi J. 76(4):95(1993). 